eCommons@AKU

January 2013

\title{
Informed consent, privacy and confidentiality practised by doctors of a tertiary care hospital in a developing country
}

Waris Qidwai

Aga Khan University, waris.qidwai@aku.edu

Rumina Tabassum

Fahad Hanif Khan

Salman Javed

Syed Mustafa Ali

See next page for additional authors

Follow this and additional works at: https://ecommons.aku.edu/pakistan_fhs_mc_fam_med Part of the Family Medicine Commons

\section{Recommended Citation}

Qidwai, W., Tabassum, R., Khan, F., Javed, S., Ali, S., Nanji, K. (2013). Informed consent, privacy and confidentiality practised by doctors of a tertiary care hospital in a developing country. Indian Journal of Medical Ethics, 10(1), 36-40.

Available at: https://ecommons.aku.edu/pakistan_fhs_mc_fam_med/103 
Authors

Waris Qidwai, Rumina Tabassum, Fahad Hanif Khan, Salman Javed, Syed Mustafa Ali, and Kashmira Nanji 


\title{
Informed consent, privacy and confidentiality practised by doctors of a tertiary care hospital in a developing country
}

\author{
WARIS QIDWAI', RUMINA TABASSUM ${ }^{2}$, FAHAD HANIF KHAN ${ }^{3}$, SALMAN JAVED ${ }^{3}$, SYED MUSTAFA ALI ${ }^{3}$, KASHMIRA NANJI $^{4}$
}

'Professor and Chairman, Department of Family Medicine, Aga Khan University, Karachi 74800 PAKISTAN ${ }^{2}$ Associate Professor, Dow International Medical College, DUHS, Karachi 74200 PAKISTAN, ${ }^{3}$ Medical Student, Dow Medical College, Karachi 74200 PAKISTAN, ${ }^{4}$ Senior Instructor (Research), Aga Khan University, Karachi 74800 PAKISTAN. Corresponding Author: Kashmira Nanji e-mail: kashmira.nanji@aku.edu

\section{Abstract}

Background: This aim of this study was to assess the degree to which the doctors of a public sector hospital in Karachi adhere to medical ethics during their consultations.

\begin{abstract}
Material and methods: A cross-sectional study was conducted in Civil Hospital, Karachi, Pakistan, during April-June 2010. 337 patients from Out Patients Departments (OPDs) and wards were recruited through consecutive sampling. A pre-tested structured questionnaire was administered to the participants and they were asked about their demographic profile, and their doctor's practices regarding obtaining informed consent, respecting privacy and confidentiality, and treatment modalities. Written informed consent was taken from all the participants. Data was analysed using SPSS version 16.0, and a p-value of $<0.05$ was considered as statistically significant.
\end{abstract}

Results: The mean age of the study population was $38.4 \pm$ 15.0 years. There was an equal ratio of males and females. Our study showed that informed consent was obtained from $66.4 \%$ of patients. $56.9 \%$ of patients responded that they were not informed about the side effects of the prescribed medicines. $74 \%$ females were satisfied with the privacy maintained during the consultation. $64.8 \%$ were assured of the confidentiality of their information. Regarding advertisement by doctors, $46.5 \%$ of patients said it should be done.

Conclusion: There has been a marked improvement as compared with the previous practices of biomedical ethics by the doctors of this public sector hospital. However, awareness sessions should be conducted to update/ improve the knowledge of ethics among doctors to help them translate their knowledge into practice.

\section{Introduction}

Biomedical ethics is the study of morality in medicine $(1,2)$. This morality is concerned with the relationship between the doctor and patient. Throughout history, the doctor's primary moral responsibility has been to do no harm. However, with increased awareness of an individual's rights (3) doctors need to revisit the subject of medical ethics. The elementary concepts of medical ethics include: informed consent, privacy and confidentiality (2).

Numerous studies have suggested that doctors in routine clinical practice do not consider it necessary to obtain proper consent after providing patients with thorough information
(4-6). Similarly, though respect for privacy and confidentiality has also been a responsibility of doctors throughout history ( 2 , 7-8), it has been noted that doctors often neglect this aspect of medical ethics.

There are well-established ethical frameworks in the field of medicine in the western world $(2,9)$, with appropriate state laws and codes of ethics. However, despite the fact that the regulatory body for medicine, the Pakistan Medical and Dental Council (PMDC), has formulated a code of ethics for doctors, no significant steps have been taken to ensure its implementation (10).

In recent times, there has been a change in the thinking of patients, mainly due to the greater influence of information technology, primarily of the electronic media (radio and television) and the internet (3). Thus, due to increasing awareness, patients demand to be fully informed about options, treatment plans and possible complications, aspects which were not present in the past (3).

Considering this changing trend and level of awareness, this study was conducted at a public sector hospital in Karachi, to determine the degree to which ethical codes of medicine have been put into practice according to the patient perspective.

\section{Material and methods}

This cross-sectional survey was conducted in the Civil Hospital (CHK), a tertiary care hospital in Karachi, the largest city in, and economic hub of, Pakistan. The data were collected from April to June 2010. Patients between 18 to 60 years visiting the Out Patients Department (OPD) or admitted into the wards were recruited through consecutive sampling. However, patients who had been admitted for severe burn injuries; or diagnosed with any serious psychiatric disorder (such as schizophrenia, mood disorders); or were agitated due to severe pain, and/ or comatose; or had a hearing difficulty or a language barrier were excluded. Patients admitted into the Intensive Care Unit (ICU) and those visiting the Emergency Department were also excluded.

Totally 337 patients were recruited; on the basis of the assumption that $50 \%$ of the doctors in Pakistan respect confidentiality and privacy and obtain informed consent from their patients. The number was also chosen to obtain maximum variance with $6 \%$ bound on error and an addition of $25 \%$ for non-responders. The final sample size was approximately 
337 patients. A pre-tested structured questionnaire was administered to collect information. Pre-testing was done on $5 \%$ (17 patients) of the sample size and any changes deemed necessary were made. The questionnaire comprised two sections. The first section had information on the sociodemographic profile of patients including age, sex and marital status. The second section had questions on doctors' practice of obtaining informed consent: whether written/verbal informed consent was obtained; whether patients were informed about the indications for a treatment, possible side-effects, alternative treatments, the expected benefit of the treatment, etc.), privacy, confidentiality, doctors advertisement etc. The questionnaire was developed in English and then back translated for accuracy. The questionnaire required approximately 30 minutes to complete. Data were collected by medical students specifically trained for this task.

The Ethics Review Board (ERB) of Dow University of Health Sciences (DUHS) reviewed and approved the study. Written informed consent was obtained from the participants after the study protocol was explained to them and they were assured of the confidentiality and anonymity of the information.

\section{Statistical analysis}

Data were entered and analysed using Statistical Package for Social Sciences (SPSS) version 16.0. Normality of the data was assessed and mean and standard deviation were computed for continuous and proportions for the categorical variables. To determine the differences between gender, chi-square or Fisher's exact test was applied as appropriate and a p-value of less than 0.05 was considered statistically significant.

\section{Results}

337 patients were interviewed. There were 169 males and 168 females ( $M: F=1: 1$ ). The mean age of study participants was $38.4 \pm 15$ years. The baseline characteristics of the study participants are presented in Table 1.

Our study showed that $66.4 \%$ of the total patients reported that doctors had taken informed consent. There was no significant association of written/verbal informed consent with gender, education and location (OPD or wards), estimated through the chi-square test. Overall, $73 \%$ of patients reported being assured about the confidentiality of their information. Approximately $80.4 \%$ of the male patients reported being assured of confidentiality of information as compared to their female counter parts $(P=0.003)$. However, according to $39 \%$ of male participants, proper privacy was not maintained during their clinical examination (Table 2).

$28.5 \%$ out of 133 illiterate patients responded that they were not told about the disease from which they were suffering $(P=0.006)$, making it more difficult for them to avail of better treatment options. Approximately $62 \%(\mathrm{P}=0.017)$ of patients educated below the matric level were told about the action of the medication. However, 53\% ( $\mathrm{P}=0.004)$ of them were not briefed on the side-effects of prescribed medicines. An equal percentage reported that their doctors did not explain alternative options to their patients $(P=0.001)$ on observing those side-effects (Table 3).

It was interesting to note that while $48.3 \%$ patients were influenced by doctors' advertisements, $46.2 \%$ were not influenced by these advertisements ( $P=0.0001)$ (Table 4).

Figure 1 depicts that $51 \%$ of the patients were in favor of doctors' advertisements. Nevertheless, about $31 \%$ patient responded that they were not in favour of doctors' advertisements.

\section{Discussion}

Many studies have shown that patients depend on their doctors for all decisions regarding their illness and its treatment (11). Studies from South Africa (12) and Lithuania (13), also report that the practice of medical ethics by doctors is not satisfactory and often does not meet legal requirements.

In this study, we set out to determine the extent to which medical ethics is practised by doctors. The proportion of patients in our study population reporting that their doctor took their informed consent is higher than that in other studies conducted in Pakistan (14). In our study informed consent was not taken from almost $30 \%$ of the patients. A study conducted by Humayun et al in Lahore (2) reported that informed consent was not taken from about $90 \%$ of the patients at a public sector hospital. This observed difference in study results may be due to the fact that our study was conducted at a teaching hospital where doctors may tend to adhere more to the principles of medical ethics as compared to those at non-teaching hospitals.

A doctor must address five issues in order to take complete informed consent: the nature of the proposed procedure, its purpose, the risks, the benefits, and the availability of alternatives (15). Our study also highlights the extent to which a physician discusses his clinical decisions with the patient. The results show that there was a significant association between the patient's level of education and the patient's questioning the doctor about his diagnosis. In the study laboratory investigations and other relevant findings did not have significant association with the level of education of the patients (Table 3). However, the level of education was significantly related to the reported effects, side-effects and alternatives on observing side effects. These statistically significant associations emphasise the fact that there is an increasing awareness about healthcare and this has altered the public's thinking; people are now more eager to know their complete medical status and the treatment options available.

The study also looked at doctors' practice of maintaining confidentiality. Only $14 \%$ of the patients were not completely sure that their confidentiality was maintained. This was quite different from other local and international data $(2,16)$ With regard to privacy as well, other reported studies have had a less satisfactory rate as compared to ours. A study conducted in Karachi (17) showed that $46 \%$ of patients complained of improper protection of privacy; $30 \%$ of patients in our study 
had this complaint. These findings, of an improved system of informed consent, and better maintenance of privacy and confidentiality, are important as this enables the patient to speak frankly of their history and symptoms with the doctors (16).

The opinion of patients on doctors advertising was unanticipated. $48.3 \%$ of the sample approved of advertising, despite the fact that this topic has been a matter of debate globally. A handful of authors, in recent publications throughout the world, have argued in favour of doctors advertising (18). They have asserted that, as long as the advertisement does not contain any false or deceptive information, it is acceptable (18). In our study, $46.2 \%$ of the patients stated that they were not influenced by advertisements, as compared to $42.4 \%$ of participants who were so influenced. The inference which could be drawn from the result was that professional advertisements were acceptable provided the main intention of any advertisement regarding a doctor's services is to present the information required by the patient to make a decision about the aptness and availability of the health services offered. According to the PMDC, a doctor may advertise his services but only if he observes the code of ethical conduct. The advertisement should not exaggerate or mislead the public about the services (19). However, to the best of our knowledge, this aspect of medical ethics has not been put before patients in earlier studies, and future research into this intriguing aspect could yield more insights.

As previously mentioned, the role of the doctor as sole decision maker is changing. A study conducted in 1998(20) reported that patients were satisfied with the fact that doctors were the ones making decisions for them. Similar results were seen in another study in Malaysia and in Kashmir in 2007 (11). However, with the public's growing awareness, people demand to be fully informed of all clinical aspects (3).

This study has several potential limitations. The study was conducted in a single hospital, and the results cannot be generalised for all public sector hospitals in Pakistan. Second, the participants recruited from the OPD were interviewed just after their session with the doctors; while those patients in the wards were interviewed at different times, which might have led to a limitation to recall bias.

\section{Conclusion}

The results of this study suggest that doctors at teaching hospitals may have improved in the practice of ethics. However, since the data were collected only at one teaching hospital, we cannot comment on the ethical practices of physicians from the private healthcare sector. Nonetheless, to encourage ethical medical practice, steps should be taken to highlight the importance of the basic principles of ethics: informed consent, privacy and confidentiality. Furthermore, awareness building should be conducted for doctors to improve and refresh their knowledge of ethical principles. Finally, professional advertisements by doctors should not contain any information that can be misleading for the patient.

\section{Acknowledgements}

We are grateful to the management and staff of the Civil Hospital Karachi for their support throughout the data collection phase. We are also grateful to all the study participants for their participation in this study.

Table 1: Demographic profile of the study participants $(n=337)$

\begin{tabular}{|c|c|c|}
\hline Characteristic & $\mathrm{n}$ & $(\%)$ \\
\hline $\begin{array}{l}\text { Gender } \\
\text { Male }\end{array}$ & 169 & $(50.1)$ \\
\hline $\begin{array}{l}\text { Marital status } \\
\text { Married }\end{array}$ & 263 & (78) \\
\hline Education & & \\
\hline Illiterate & 133 & (39.4) \\
\hline Below matric & 127 & (37.6) \\
\hline Matriculation and above & 77 & $(22.8)$ \\
\hline Occupation & & \\
\hline Private & 33 & (9.7) \\
\hline Government & 37 & (10.9) \\
\hline Self-employed & 81 & $(24.0)$ \\
\hline Retired & 42 & $(12.4)$ \\
\hline Housewife & 121 & (35.9) \\
\hline Student & 5 & $(1.4)$ \\
\hline Unemployed & 18 & $(5.3)$ \\
\hline
\end{tabular}

${ }^{*}$ Mean (SD)

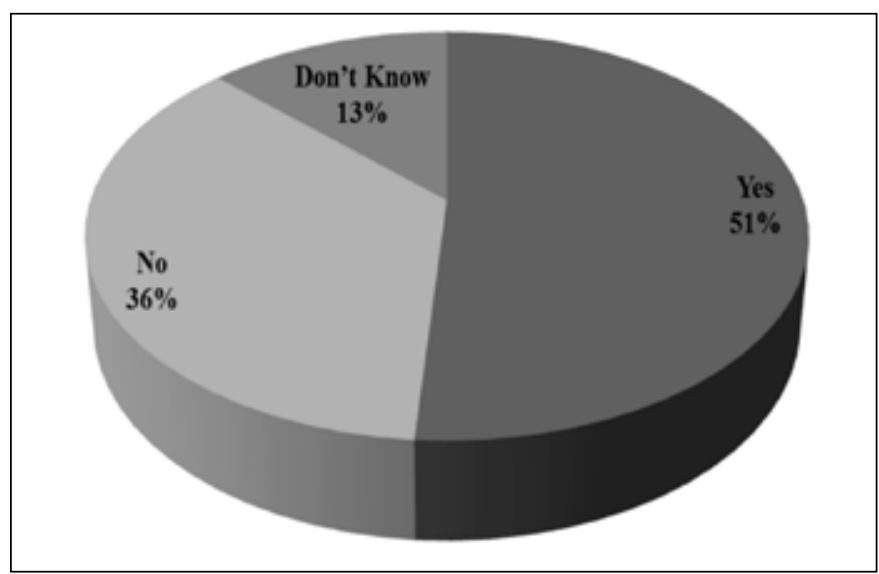

Figure 1: Patient responses on professional advertisement by doctors 
Table 2: Patients' perceptions about doctor's practice regarding consent process and gender specific differences in Karachi Pakistan ( $n=337)$

\begin{tabular}{llrrr}
\hline & & Male & Female & P-Value* \\
Characteristics & & $(169)$ & $(168)$ & \\
& & $n(\%)$ & $n(\%)$ & \\
\hline Consent taken & Yes & $106(62.7)$ & $118(70.2)$ & 0.315 \\
& No & $57(33.7)$ & $44(26.2)$ & \\
& Don't know & $6(3.5)$ & $6(3.5)$ & 0.003 \\
\hline Confidentiality assured & Yes & $136(80.4)$ & $109(64.8)$ & \\
& No & $14(8.2)$ & $33(19.6)$ & 0.033 \\
& Don't know & $19(11.2)$ & $26(15.4)$ & \\
\hline Privacy maintained & Yes & $103(60.9)$ & $112(66.6)$ & $31(19.8)$ \\
& No & $54(32.0)$ & $23(13.6)$ & \\
& Don't know & $12(7.1)$ & & \\
\hline
\end{tabular}

${ }^{*}$ Chi-square test, P-value: difference in males and females, significance at $<0.05$

Table 3: Information provided by doctors to patients according to their level of education in Karachi Pakistan

\begin{tabular}{lcccc}
\hline \multicolumn{1}{c}{ Characteristics } & \multicolumn{2}{c}{ Level of education§ } & \\
\cline { 1 - 3 } & $\begin{array}{r}\text { Illiterate } \\
(133) \\
\mathrm{n}(\%)\end{array}$ & $\begin{array}{c}<10(127) \\
\mathrm{n}(\%)\end{array}$ & $\mathrm{n}$-value* \\
\hline Informed about the diagnosis & $95(71.4)$ & $108(85.0)$ & $67(87.0)$ & 0.006 \\
\hline Reason for investigations & $72(54.1)$ & $87(68.5)$ & $47(61.0)$ & 0.084 \\
\hline Discussion of relevant lab findings & $89(66.9)$ & $89(70.0)$ & $47(61.0)$ & 0.454 \\
\hline Explained role of the drugs & $63(47.3)$ & $79(62.2)$ & $31(40.2)$ & 0.017 \\
\hline Explained side-effect of the drugs & $51(38.3)$ & $59(46.4)$ & $35(45.5)$ & 0.004 \\
\hline Alternative on observing side-effects & $62(46.6)$ & $57(44.9)$ & $33(42.8)$ & 0.000 \\
\hline
\end{tabular}

${ }^{*}$ Chi -square test P-value: difference in level of education, significance set at $<0.05$

§Level of Education: Illiterate: no formal education, $<10=$ less than 10 years of schooling, $>10=$ more than 10 years of schooling

Table 4: Views of patients regarding the professional advertisement of doctors in Karachi Pakistan

Characteristic

\begin{tabular}{|c|c|c|c|c|c|}
\hline & & Yes (163) & No (113) & Don't Know (61) & P-Value* \\
\hline \multirow{3}{*}{$\begin{array}{l}\text { Influenced by } \\
\text { advertisement }\end{array}$} & Yes & $\begin{array}{r}107 \\
(31.8)\end{array}$ & $22(6.6)$ & $14(4.2)$ & \multirow{3}{*}{0.0001} \\
\hline & No & $50(14.8)$ & $87(25.8)$ & $19(5.6)$ & \\
\hline & Don't know & $6(1.7)$ & $4(1.2)$ & $28(8.3)$ & \\
\hline
\end{tabular}

\section{Should doctors' advertisements be done?}

*Chi-square test 


\section{References}

1. McCullough LB, Chervenak FA. Informed consent. Clin Perinatol. 2007Jun;34(2): 275-85, vi.

2. Humayun A, Fatima N, Naqqash S, Hussain S, Rasheed A, Imtiaz H, Imam SZ. Patients' perception and actual practice of informed consent, privacy and confidentiality in general medical outpatient departments of two tertiary care hospitals of Lahore. BMC Medical Ethics. 2008Sep 25;9:14.

3. Shamim MS. Medical Ethics: A slow but sustained revolution in Pakistan's healthcare. J Pak Med Assoc. 2010Sep;60(9): 706-7.

4. Jafarey $A M$, Farooqui $A$. Informed consent in the Pakistani milieu: the physician's perspective. J Med Ethics. 2005 Feb;31(2):93-6.

5. Khan RI. Informed consent and some of its problems in Pakistan. J Pak Med Assoc. 2008 Feb;58(2): 82-4.

6. Qidwai W, Qureshi H, Azam SI, Ali SS, Ayub S. Perception of bioethics among general practitioners in Karachi. Pak J Med Sci. 2002;18(3): 2216.

7. Moskop JC, Marco CA, Larkin GL, Geiderman JM, Derse AR . From Hippocrates to HIPAA: privacy and confidentiality in emergency medicine: Part I. Conceptual, moral and legal foundations. Ann Emerg Med. 2005 Jan;45(1):53-9.

8. Geiderman JM, Moskop JC, Derse AR. Privacy and confidentiality in emergency medicine: obligations and challenges. Emerg Med Clin North Am. 2006 Aug;24(3):633-56.

9. Searight HR, Gafford J. Cultural diversity at the end of life: issues and guidelines for family physicians. Am Fam Physician. 2005 Feb 1;71(3): 515-22.

10. Shiraz B, Shamim MS, Shamim MS, Ahmed A. Medical ethics in surgical wards: knowledge, attitude and practice of surgical team members in Karachi. Indian J Med Ethics. 2005Jul-Sep;2(3): 94-6.

11. Yousaf RM, Fauzi ARM, How SH, Rasool AG, Rehana K. Awareness, knowledge and attitude towards informed consent among doctors in two different cultures in Asia: a cross sectional comparative study in
Malaysia and Kashmir, India. Singapore Med J. 2007Jun;48(6): 559-65.

12. Liseckiene I, Liubarskiene Z, Jacobsen R, Valius L, Norup M. Do family practitioners in Lithuania inform their patients about adverse effects of common medications? J Med Ethics. 2008 Mar;34(3): 137-40.

13. Henley L, Benatar SR, Robertson BA, Ensink K. Informed consent-a survey of doctors' practices in South Africa.S Afr Med J. 1995 Dec;85(12): 1273-8.

14. Amin FM, Jawaid M, Rehman S, Mudassir, Hina, Zakai SB . An audit of information provided during preoperative informed consent. Pak J Med Sci. 2006;22:10-13.

15. Bhurgri $\mathrm{H}$, Qidwai W. Awareness of the process of informed consent among family practice patients in Karachi.J Pak Med Assoc.Jul;54(7):398401.

16. Shrier I, Green S, Solin J, Duarte-Franco E, Guibert R, Brousseau G, Khanlou N. Knowledge of and attitude toward patient confidentiality within three family medicine teaching units. Acad Med. 1998 Jun;73(6): 710-12.

17. Imam SZ, Syed SK, Ali SU, Fatima K, Gill M, Hassan MO, Hashmi SH, Siddiqi MT, Khan HM, Jameel OF. Patients' satisfaction and opinions of their experiences during admission in a tertiary care hospital in Pakistan: a cross sectional study. BMC Health Serv Res. 2007Oct 3;7:161

18. Pandya SK. Advertising remains unethical even in the digital age. Indian J Med Ethics. 2001Jan-Mar;9(1):15.

19. Pakistan Medical and Dental Council[Internet]: Pakistan: PMDC: c2006. Part V, Complaint against medical or dental practitioner and action thereon. [date unknown. cited 2013 Jan21]; [about 3 screens]. Available from: http://www.pmdc.org.pk/Ethics/tabid/101/Default.aspx\#15

20. Asai A, Kishino M, Tsuguya F, Sakai M,Yokota M, Nakata K, Sasakabe S, Sawada K, Kaiji F. A report from Japan: choices of Japanese patients in the face of disagreement. Bioethics. 1998Apr;12(2): 162-72.

\section{If you are looking for India's finest medical journal, then here it is.}

The National Medical Journal of India is a premier bi-monthly multi-disciplinary health sciences journal which publishes original research, reviews, and other articles relevant to the practice of medicine in India. The journal aims to instruct, inform, entertain and provide a forum for the discussion of social, economic and political health issues. It is included in the Index Medicus

\begin{tabular}{|c|c|c|c|c|}
\hline \multicolumn{4}{|c|}{ SUBSCRIPTIONS } & \multirow[b]{2}{*}{ Five years } \\
\hline & One year & Two years & Three years & \\
\hline Indian & Rs 600 & Rs 1100 & Rs 1600 & Rs 2600 \\
\hline Overseas & US \$85 & US \$150 & US\$220 & US\$365 \\
\hline
\end{tabular}

(Pubmed), Excerpta Medica (EmBase), BIOSIS, Current Contents/Clinical Medicine and Science Citation Index.

Personal subscriptions paid from personal funds are available at $50 \%$ discounted rates

Bank draft/cheque should be made in favour of The National Medical Journal of India. Please add Rs 75 for outstation cheques. Journals can be sent by registered post on request at an added cost of Rs 90 per annum. Requests to be made at the time of subscribing.

Please send your subscriptions, queries to:

The Subscription Department, The National Medical Journal of India, All India Institute of Medical Sciences, Ansari Nagar, New Delhi 110029.

Tel:91-11-26588802ＦAX:91-11-26588663Ｅ-mail:nmji@nmji.inＷebsite:www.nmji.in

The National Medical Journal of India

On the frontline of Indian medicine 